\title{
STUDIES ON STREPTOCARPUS
}

\section{GENETICS OF FLOWER COLOUR PATTERNS \\ W. J. C. LAWRENCE}

John Innes Horticultural Institution, Bayfordbury, Hertford, Herts

Received 18.ii. 57

\section{INTRODUCTION}

IN a previous paper (Lawrence and Sturgess, 1957) data were given for the chemical constitution and inheritance of the main anthocyanin pigments found in flowers of garden forms of Streptocarpus $(2 n=32)$ and in the species and their hybrids.

It was shown that $V$ genotypes have anthocyanin in their flower stems (and to a lesser extent in the leaves) but not in their flowers; $v F$ genotypes have anthocyanin in neither their stems nor their flowers; while $V F$ genotypes have pale anthocyanin in their flowers as well as pigmented stems. Consequently $V$ and $F$ act as complementary genes governing the production of anthocyanin in the flowers. A third gene, $I$, increases the amount of anthocyanin in the flowers, giving colour of medium to deep intensity in place of pale, $i$. $V, F$ and $I$ control the production of anthocyanin in the flowers apparently irrespective of the nature of the pigment, while the production of specific anthocyanins is determined by alleles $\mathrm{Oo}, \mathrm{Rr}$ and $D d$ which, in their appropriate combinations, give malvidin, peonidin, and pelargonidin glycosides.

\section{PATTERN IN THE GARDEN FORMS}

In this paper, data are given for the inheritance of four flower colour patterns.

(i) anthocyanin blotch $(B)$ within the corolla tube.

(ii) anthocyanin $(H)$ in capitate hairs on the pistil.

(iii) anthocyanin lines $(L)$ on the petals.

(iv) yellow pigment $(Y)$ in a central stripe down the corolla tube.

In a given genotype, the main pigment in the lines has been identified as being the same as that in the petals.

Table I gives the genotypes for some contrasted phenotypes. It should be noted that the occurrence of coloured capitate hairs $(H)$ and of lines $(L)$ is conditional upon the presence of $V$; and the occurrence of blotch $(B)$ upon the presence of $V$ and $F$.

\section{(a) Inheritance of $\mathrm{F}, \mathrm{I}, \mathrm{B}$ and $\mathrm{H}$}

The detailed phenotypic effect of these genes in the presence of $V$ is as follows ; $F$ produces anthocyanin uniformly in the epidermal cells of the whole corolla. $I$ intensifies this colour. $B$ produces a 
blotch of deeper anthocyanin on the anterior portion of the inside of the corolla tube around the point of insertion of the anther filaments.

TABLE I

Distribution of anthocyanin in the plant

\begin{tabular}{|c|c|c|c|c|c|}
\hline \multirow[b]{2}{*}{ Genotype } & \multicolumn{5}{|c|}{ Phenotype } \\
\hline & $\begin{array}{l}\text { Corolla } \\
\qquad(F)\end{array}$ & $\begin{array}{l}\text { Corolla } \\
\text { tube blotch } \\
\quad(B)\end{array}$ & $\begin{array}{l}\text { Pistil } \\
\text { hairs } \\
(H)\end{array}$ & $\begin{array}{l}\text { Lines } \\
(L)\end{array}$ & $\begin{array}{l}\text { Flower } \\
\text { stems and } \\
\text { foliage }\end{array}$ \\
\hline \begin{tabular}{l|l}
$v f$ & $b h l$ \\
$v F i$ & $B H L$ \\
$V f$ & $b h l$ \\
$V f$ & $b H L$ \\
$V F i$ & $b h l$ \\
$V F i$ & $B H L$ \\
$V F i$ & $B H L$ \\
$V F I$ & $b h l$ \\
$V F I$ & $B H L$
\end{tabular} & $\begin{array}{l}- \\
- \\
\overline{+} \\
+ \\
+ \\
++ \\
++\end{array}$ & $\begin{array}{c}- \\
- \\
= \\
\overline{+} \\
\pm \\
++?\end{array}$ & $\begin{array}{c}- \\
\overline{+} \\
\frac{+}{+} \\
\pm \\
++?\end{array}$ & $\begin{array}{c}- \\
\bar{t} \\
\overline{+} \\
\pm++3\end{array}$ & $\begin{array}{l}- \\
+ \\
+ \\
+ \\
+ \\
+ \\
+\end{array}$ \\
\hline
\end{tabular}

$H$ produces anthocyanin in the stalks of the glandular hairs on the pistil but not in the intermingled eglandular hairs.

The inheritance of $F$ has been given previously (Lawrence and Sturgess, 1957). The breeding results were consistent with respect

TABLE 2

Inheritance of blotch $(\mathrm{B})$ and hair colour $(\mathrm{H})$

\begin{tabular}{|c|c|c|c|c|c|c|}
\hline \multirow{2}{*}{ Genes } & \multirow{2}{*}{$\begin{array}{l}\text { No. of } \\
\text { families }\end{array}$} & \multirow{2}{*}{$X: x$} & \multicolumn{2}{|c|}{$\chi 2$} & \multirow[b]{2}{*}{ D.F. } & \multirow[b]{2}{*}{$P$} \\
\hline & & & $\begin{array}{l}\text { Deviation } \\
\text { from }\end{array}$ & $\begin{array}{l}\text { Hetero- } \\
\text { geneity }\end{array}$ & & \\
\hline$B b$ & 25 & $\begin{array}{c}B_{I} \\
585: 542\end{array}$ & $\begin{array}{l}I: I \\
I \cdot 6_{4} \mathrm{I}\end{array}$ & $\begin{array}{c}\cdots \\
2 \mathrm{I} \cdot 402\end{array}$ & $\begin{array}{r}1 \\
24\end{array}$ & $\begin{array}{l}0.20 \\
0.7-0.5\end{array}$ \\
\hline$H h$ & 17 & $429: 374$ & $3 \cdot 767$ & $\begin{array}{c}\ldots \\
13 \cdot 152\end{array}$ & $\begin{array}{r}I \\
16\end{array}$ & $\begin{array}{l}0.1-0.05 \\
0.7-0.5\end{array}$ \\
\hline$B b$ & 24 & $\begin{array}{c}F_{2} \\
1006: 350\end{array}$ & $\begin{array}{l}3: 1 \\
0 \cdot 16_{4}\end{array}$ & $\begin{array}{c}\cdots \\
19 \cdot 118\end{array}$ & $\begin{array}{r}1 \\
23\end{array}$ & $\begin{array}{l}0.7-0.5 \\
0.7\end{array}$ \\
\hline $\begin{array}{c}H h \\
\text { (FF plants only) }\end{array}$ & 20 & $862: 25 I$ & $3 \cdot 690$ & 13.872 & $\begin{array}{r}1 \\
19\end{array}$ & $\begin{array}{l}0.1-0.05 \\
0.8-0 \cdot 7\end{array}$ \\
\hline
\end{tabular}

to the expected genotypes, but in the majority of families there was a deficiency of $F$ individuals. The inheritance of $I$ was also given and was straightforward. The inheritance of $B$ and $H$, separately, is shown in table 2, and is, basically, monohybrid. The expected $B, b$ phenotypes always occur but in some cases, omitted from the summarised data in the table and to be discussed later, there are significant deviations from expectation. A similar situation is found 
with respect to $H, h$ phenotypes in families homozygous for $F$, table 2 . In families segregating for $F, 64$ per cent. show a marked deficiency of Fh genotypes. We may summarise the data so far presented by saying that the inheritance of all four dominant genes, considered separately, is monohybrid, but often there is a deficiency of cyanic individuals in families segregating for both $F$ and $H$.

The reason for these deficiencies becomes clear when the data are examined for the combined inheritance of $F, I, B$ and $H$. These "genes" are then seen to behave as if they occur very nearly at the same locus and comprise a complex or supergene, a postulation which will be examined in detail later. Throughout this paper the terms gene and allele will be used to describe the components of the supergene, without prejudice to their precise nature, location or action.

TABLE 3

Garden form genotypes

\begin{tabular}{|c|c|c|c|c|c|c|c|}
\hline Class & 1 & 2 & 3 & 4 & 5 & 6 & 7 \\
\hline Genotype & $\frac{F i B H}{\operatorname{Ii} B \bar{H}(r)}(r)$ & $\frac{F i B H}{F I b h(d)}$ & $\frac{F I b h}{\overline{F I}(d)}(d)$ & $\frac{F i B H}{f i b H}(p)$ & $\frac{F I b h(d)}{f i b H(p)}$ & $\frac{f i b H}{f i b H}(p)$ & $\frac{F I b H}{f i b H}$ \\
\hline $\begin{array}{c}\text { No. of plants } \\
\text { identified }\end{array}$ & 13 & 16 & 65 & 22 & 28 & 6 & 3 \\
\hline
\end{tabular}

* ancestral gametes : $r=$ rexii, $d=$ dunnii, $p=$ parviflorus.

(i) Evidence from the parents. $F, I, B$ and $H$ genotypes have been identified in 153 garden parents. These fall into only 7 classes instead of the 8I expected from the independent inheritance of four pairs of alleles (table 3 ).

With the exception of the three class 7 individuals, these results can be interpreted on the basis of complete linkage, the six genotypic classes being derived from the combinations of three types of gamete, viz. FiBH, FIbh and $f i b H$. These six classes are readily identified by sight in respect of $F, B$ and $H$ but the cumulative effects of both $F$ and $I$ often prevent reliable identification of $I$ phenotypes. However, once a genotype has been determined in respect of the other three genes, its constitution for $I$ can be inferred on the basis of complete linkage, pedigrees can be examined, and proof obtained by breeding. This has been done in many cases.

The sequence of the four pairs of alleles on the chromosome is not known. The order in which they are given is based on the extent (area) of their action : $F$ and $I$ are concerned with the pigmentation of the whole flower whereas $B$ and $H$ are concerned with highly limited areas.

We have now to find an explanation for the occurrence of the three exceptional class 7 genotypes. Their parents and progeny are 
TABLE 4

Origin, constitution and progeny of the anomalous types $6^{6} / 34,4^{7} / 36$ and $69^{19} / 36$

\begin{tabular}{|c|c|c|c|c|c|}
\hline \multicolumn{2}{|c|}{ Parents } & \multicolumn{4}{|c|}{ Progeny } \\
\hline \multirow[b]{2}{*}{ Female } & \multirow[b]{2}{*}{ Male } & \multirow[b]{2}{*}{ Expected types } & \multirow{2}{*}{$\begin{array}{l}\text { Number } \\
\text { observed }\end{array}$} & \multicolumn{2}{|c|}{ Number expected } \\
\hline & & & & $\begin{array}{c}\text { Full } \\
\text { viability }\end{array}$ & $\begin{array}{l}\text { Zygotic } \\
\text { lethality }\end{array}$ \\
\hline $3 / 33 \frac{F I b h}{F i B H}$ & $1 / 33 \frac{f b H}{f i b H}$ & 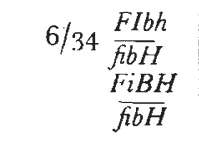 & $\begin{array}{l}45 \\
54\end{array}$ & $\begin{array}{l}49 \cdot 5 \\
49 \cdot 5\end{array}$ & $\begin{array}{l}49 \cdot 5 \\
49 \cdot 5\end{array}$ \\
\hline 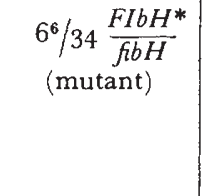 & selfed & $\begin{array}{c}\text { I 4/35 } \frac{F I b H}{F I b H} \\
\frac{F I b H}{f i b H} \\
\frac{f b H}{f i b H}\end{array}$ & $\begin{array}{r}0 \\
43 \\
31\end{array}$ & $\begin{array}{l}\text { I } 8 \cdot 5 \\
37 \cdot 0 \\
\text { I } 8 \cdot 5\end{array}$ & $\begin{array}{l}\text { lethal } \\
49 \cdot 3 \\
24 \cdot 7\end{array}$ \\
\hline $1 / 33 \frac{f b H}{f i b H}$ & $6^{6} / 34 \frac{F I b H}{f i b H}$ & $\begin{array}{c}25 / 35 \frac{f i b H}{\overline{F I b H}} \\
\frac{f b H}{\overline{f i b H}}\end{array}$ & $\begin{array}{l}35 \\
36\end{array}$ & $\begin{array}{l}35 \cdot 5 \\
35 \cdot 5\end{array}$ & $\begin{array}{l}35 \cdot 5 \\
35 \cdot 5\end{array}$ \\
\hline $15 / 34 \frac{F I b h}{F i B H}$ & $14^{4} / 34 \frac{f b H}{\bar{F} b b h}$ & $\begin{array}{c}4 / 36 \frac{F I b h}{\overline{f i b H}} \\
F I b h \\
\overline{F I b h} \\
F i B H \\
\overline{f i b H} \\
\frac{F i B H}{F I b h}\end{array}$ & $\begin{array}{l}5 \mathrm{I} \\
24 \\
8 \mathrm{I}\end{array}$ & $\begin{array}{l}39 \cdot 0 \\
39 \cdot 0 \\
78 \cdot 0\end{array}$ & $\begin{array}{l}39^{\circ} 0 \\
39 \cdot 0 \\
78 \cdot 0\end{array}$ \\
\hline $4^{7 / 36} \underset{\text { (mutant) }}{\text { fibH }}$ & selfed & $\begin{aligned} & 92 / 37 \frac{F I b H}{F I b H} \\
& F I b H \\
& \overline{f i b H} \\
& \frac{f i b H}{f i b H}\end{aligned}$ & $\begin{array}{c}0 \\
28 \\
22\end{array}$ & $\begin{array}{l}12.5 \\
25.0 \\
12.5\end{array}$ & $\begin{array}{l}\text { leihal } \\
33 \cdot 3 i \\
16 \cdot 7\end{array}$ \\
\hline $28^{62} / 35 \frac{f b H}{F I b h}$ & selfed & $\begin{array}{r}69 / 36 \frac{f b H}{\overline{f b H}} \\
\frac{f b b H}{F I b h} \\
\frac{F I b h}{F I b h}\end{array}$ & 39 & $\begin{array}{l}\text { I I } \cdot 75 \\
35 \cdot 25\end{array}$ & $\begin{array}{l}\text { I I } 75 \\
35 \cdot 25\end{array}$ \\
\hline $\begin{array}{c}69^{19} / 3^{6} \frac{f b H}{F I b H^{*}} * \\
\text { (mutant) }\end{array}$ & selfed & $\begin{array}{l}82 / 3^{8} \frac{f i b H}{\overline{f b} H} \\
\frac{f b H}{\overline{F I b H}} \\
\frac{F I b H}{F I \bar{b} H}\end{array}$ & $\begin{array}{r}9 \\
20 \\
0\end{array}$ & $\begin{array}{r}7 \cdot 25 \\
14 \cdot 50 \\
7 \cdot 25\end{array}$ & $\begin{array}{l}9 \cdot 7 \\
\text { I } 9 \cdot 3 \\
\text { lethal }\end{array}$ \\
\hline $4^{2.4} / 36 \frac{F i B H}{f i b H}$ & $69^{19} / 3^{6} \frac{f b H}{F I b H}$ & $\begin{aligned} 285 / 39 & \frac{F i B H}{f i b H} \\
& \frac{F i B H}{F I b H} \\
& \frac{f b H}{F b H} \\
& \\
& \frac{f b H}{F I b H}\end{aligned}$ & $\begin{array}{l}\text { I } 3 \\
0 \\
2 \mathrm{I} \\
\text { I } 6\end{array}$ & $\begin{array}{l}12 \cdot 5 \\
12 \cdot 5 \\
12 \cdot 5 \\
12 \cdot 5\end{array}$ & $\begin{array}{l}16 \cdot 7 \\
\text { lethal } \\
16 \cdot 7 \\
16 \cdot 7\end{array}$ \\
\hline
\end{tabular}


given in table 4. First, it will be seen that, whereas from their parentage these individuals should have been heterozygous for $H$, all of them bred as if they were homozygous dominants. Secondly, on the basis of the known viable gametes and zygotes (table 3), and on the breeding results (table 4 ) all three of the class 7 genotypes must be allotted the constitution $\frac{F I b H}{f i b h}$ in which the $F I b H$ gamete is novel. Thirdly, the kinds and proportions of the cyanic phenotypes in test crosses, especially in family $25 / 35$, show that the gamete $F I b H$ is viable. Fourthly, the ratios obtained in families $14 / 35,92 / 37,82 / 38$ and $285 / 39$ indicate that the zygotes $\frac{F I b H}{F I b H}$ and $\frac{F I b H}{F i B H}$ carrying the $F I b H$ gamete are lethal. Lastly, it will be seen that the $F I b H$ gamete could have arisen by (I) crossing-over between $H$ and $h$, (2) simultaneous crossing-over between $i B$ and $I b$, or (3) by mutation of $h$ to $H$, or of $i B$ to $I b$. Whichever event was effective, the specificity and independence of the relevant loci is demonstrated.

(ii) Evidence from the progeny. The recording of the flower pattern characters dealt with in this paper was originally ancillary to the main study of the genetics and chemical constitution of the anthocyanin pigments, hence the data presented in this section are merely those that happened to come to hand. Nevertheless, they support and amplify the conclusions derived from the genotypic constitution of the parents discussed in the previous section. Table 5 gives the summarised results for linkage between the components of the supergene. Except, apparently, in two reciprocal families, $102 / 3^{8}$ and 103/38, linkage is complete. The occurrence of these exceptions is of much interest since they directly support the view that theindividuals $6^{6} / 34,4^{7} / 3^{6}$ and $69^{19} / 3^{6}$ arose by crossing-over or mutation at either one "locus" or two. In the case of these three individuals mutation, in the rroad sense, was from the heterozygous to the dominant homozygous phase, therefore it was not directly observable and could only be deduced by the breeding behaviour of the parents. In the case of families $102 / 38$ and $103 / 38$, three mutant phenotypes were directly observed. The details of their parents and progeny are given in table 6 and they show that the genotypes of the three mutants are identical. There appears to be only one explanation of their origin that fits all the facts, namely, that the $i$ locus in the white-flowered parent I/33 $\frac{f b H}{f b H}$ mutated to $I$ giving the mutant genotype $\frac{f I b H}{\overline{F i B H}}$. Crossing-over, in the superficial sense, is therefore excluded in this instance.

A further instance of crossing-over or mutation is provided by a back-cross family I $4 / 54\left(\left(\right.\right.$ rexii $\left.\left.F B \times 14^{1} / 34\right) \times 14^{1 / 34}\right)$, table 7 . The constitution of the parents $\mathrm{I}^{21} / 53$ and $\mathrm{I}_{4}^{1} / 34$ is known from a number of selfs and crosses in which they have been used. In family $14 / 54$ 
TABLE 5

Linkage summary

\begin{tabular}{|c|c|c|c|c|c|c|c|}
\hline Combination & Families & $X r$ & $X y$ & ${ }_{x} r$ & $x y$ & $\begin{array}{l}\text { Expectation } \\
\text { with complete } \\
\text { linkage }\end{array}$ & $\begin{array}{l}\text { Cross-over } \\
\text { percentage and } \\
\text { standard error }\end{array}$ \\
\hline$\frac{F B}{f b}$ selfed & I & $3^{8}$ & o & o & 16 & $3: 0: 0: 1$ & 0 \\
\hline$\frac{B H}{b h}$ selfed & 25 & 1095 & o & o & 331 & $3: 0: 0: 1$ & 0 \\
\hline$\frac{B H}{b h} \times \frac{b h}{b h}$ & 12 & 292 & 0 & 0 & $24^{\circ}$ & $I: 0: 0: I$ & 0 \\
\hline$\frac{B H}{b h} \times \frac{b H}{b h}$ & 4 & I 54 & o & 114 & $4^{8}$ & $2: 0: 1: 1$ & 0 \\
\hline$\frac{F h}{f H}$ selfed & 5 & 124 & $5^{6}$ & 62 & 0 & $2: 1: 1: 0$ & 0 \\
\hline$\frac{B i}{b I}$ selfed & 2 & IIo & 64 & 43 & o & $2: I: I: O$ & 0 \\
\hline$\frac{B i}{b I} \times \frac{b i}{b i}$ & 4 & $3^{*}$ & I 26 & I 23 & 0 & $0: 1: 1: 0$ & $\cdots$ \\
\hline$\frac{H c}{h \bar{C}} \times \frac{h c}{h c}$ & I & 6 & 9 & 9 & 6 & $\ldots$ & $40 \cdot 0 \pm 8 \cdot 9$ \\
\hline$\frac{B c}{b C} \times \frac{b c}{b c}$ & I & 6 & 20 & 17 & 7 & $\cdots$ & $26 \cdot 0 \pm 6 \cdot 2$ \\
\hline$\frac{B c}{b C} \times \frac{B c}{b c}$ & I & I 2 & 4 & I 4 & 3 & $\cdots$ & $4^{2} \cdot 0 \pm 15 \cdot 7 \dagger$ \\
\hline$\frac{C y_{2}}{c Y_{2}}$ selfed & 2 & 47 & 29 & 22 & 0 & $2: 1: 1: 0$ & o \\
\hline$\frac{r_{2} D}{y 2 d}$ selfed & I & 50 & 16 & 8 & 30 & $\ldots$ & $20 \cdot 2$ \\
\hline \multirow{3}{*}{$\begin{array}{l}\frac{r_{I} D}{y_{I} d} \text { selfed } \\
\frac{r_{I} D}{y_{I} d} \times \frac{y_{I} d}{y_{I} d} \\
\frac{r_{I} D}{y_{I} d} \times \frac{y_{I} D}{y_{I} d}\end{array}$} & I & 22 & 5 & I 6 & 12 & $\ldots$ & \multirow{3}{*}{$\left.\begin{array}{c}34 \cdot 4 \\
26 \cdot 8 \pm 4 \cdot 5 \\
12 \cdot 3 \pm 10 \cdot 2\end{array}\right\} \begin{array}{c}25 \cdot 3 \pm \\
4 \cdot 2\end{array}$} \\
\hline & 2 & 34 & 13 & 13 & 37 & $\cdots$ & \\
\hline & 1 & I 6 & I & 12 & 9 & $\cdots$ & \\
\hline \multirow{2}{*}{$\begin{array}{l}\frac{D l}{d L} \text { selfed } \\
\frac{D l}{d L} \times \frac{d l}{d l}\end{array}$} & 2 & 85 & 19 & 55 & o & $\cdots$ & \multirow{2}{*}{$22 \cdot 8 \pm 2 \cdot 7 \pm$} \\
\hline & 7 & $5^{6}$ & I 24 & I 64 & 33 & $\cdots$ & \\
\hline
\end{tabular}

* = mutants, see families $102-3 / 38$, table 6 .

$\dagger=$ by maximum likelihood.

$\ddagger=$ based on a differential survival rate of $l l$ genotypes estimated as $64 \cdot 5+6 \cdot 1$ per cent. 
TABLE 6

Origin, constitution and progeny of anomalous types $102^{32} / 38,103^{8} / 3^{8}$ and $103^{40} / 3^{8}$

\begin{tabular}{|c|c|c|c|c|}
\hline \multicolumn{2}{|c|}{ Parents } & \multicolumn{3}{|c|}{ Progeny } \\
\hline Female & Male & Expected types & $\begin{array}{l}\text { Number } \\
\text { observed }\end{array}$ & $\begin{array}{l}\text { Number } \\
\text { expected }\end{array}$ \\
\hline $\mathrm{I} / 33 \frac{f b b H}{\frac{f b H}{f b H}}$ & $1634 \frac{F i B H}{F i b h}$ & $\begin{array}{l}102 / 38 \frac{f i b H}{F i B H} \\
\text { and } \\
\text { 103/38 } 8 \frac{f b H}{F I b h} \\
\frac{f l b H}{F i B H}\end{array}$ & $\begin{array}{l}45 \\
45 \\
3^{*}\end{array}$ & $\begin{array}{r}45 \\
45 \\
\ldots\end{array}$ \\
\hline $\begin{array}{l}\mathrm{IO}^{32} / 3^{8} \frac{f I b H^{*}}{F i B H} \\
\text { (mutant) }\end{array}$ & selfed & $\begin{array}{r}\frac{f I b H}{259 / 39} \overline{f I b H} \\
f I b H \\
\overline{F i B H} \\
\frac{F i B H}{F i B H}\end{array}$ & $\begin{array}{l}15 \\
31\end{array}$ & $\begin{array}{l}\text { I I } 5 \\
34 \cdot 5\end{array}$ \\
\hline${ }_{11} 6^{47} / 3^{8} \frac{F I b h}{F I b h}$ & ${ }_{102^{32} / 3^{8}} \frac{f I b H^{*}}{F i B H}$ & $\begin{array}{r}262 / 39 \frac{F I b h}{f I b H} \\
\frac{F I b h}{F i B H}\end{array}$ & $\begin{array}{l}30 \\
15\end{array}$ & $\begin{array}{l}22 \cdot 5 \\
22 \cdot 5\end{array}$ \\
\hline $\begin{array}{l}103^{8} / 3^{8} \frac{f I b H^{*}}{F i B H} \\
\quad \text { (mutant) }\end{array}$ & selfed & $\begin{array}{r}260 / 39 \frac{f I b H}{f I b H} \\
f \frac{I b H}{F i B H} \\
\frac{F i B H}{F i B H}\end{array}$ & $\begin{array}{l}\text { I I } \\
39\end{array}$ & $\begin{array}{l}12 \cdot 5 \\
37 \cdot 5\end{array}$ \\
\hline $\begin{array}{c}103^{40} / 38 \frac{f I b H^{*}}{F i B H} \\
\text { (mutant) }\end{array}$ & selfed & 261/39 $\begin{array}{r}\frac{f I b H}{J I b H} \\
\frac{f I b H}{F i B H} \\
F i B H \\
\overrightarrow{F i B H}\end{array}$ & I 2 & $\begin{array}{l}12 \cdot 25 \\
37 \cdot 75\end{array}$ \\
\hline
\end{tabular}

* = mutant gametes. 
two plants appeared having a totally new combination of the four genes, viz. FibH. There are four possibilities for the origin of this combination, (I) crossing-over between $\frac{B}{b}$ in $\mathrm{I}^{21} / 53$ to give the gamete FibH, (2) similar crossing-over between $\frac{F}{f}$ in ${ }^{21} / 53$, (3) crossing-over between $\frac{f}{F}$ in $14^{1} / 34$ and (4) crossing-over between $\frac{i}{I}$ in $14^{1} / 34$. Alternatively, mutation of $B$ to $b$ or $f$ to $F$ in $\mathrm{I}^{21} / 53$; or of $f$ to $F$ or $I$ to $i$ in $14^{1} / 34$, would give the same end result as crossing-over. Incidentally the deficiency of $\frac{F i B H}{F I b h}$ individuals is paralleled in other families in which this genotype segregates.

TABLE 7

Origin of anomalous segregates

\begin{tabular}{|c|c|c|c|c|}
\hline \multicolumn{2}{|c|}{ Parent } & \multicolumn{3}{|c|}{ Progeny } \\
\hline Female & Male & Expected types & $\begin{array}{l}\text { Number } \\
\text { observed }\end{array}$ & $\begin{array}{l}\text { Number } \\
\text { expected }\end{array}$ \\
\hline $\mathrm{I}^{21} / 53 \frac{F i B H}{\frac{f b H}{f b H}}$ & $14^{1} / 34 \frac{f b H}{F I b h}$ & 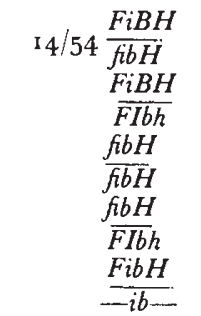 & $\begin{array}{c}\text { It } \\
3 \\
\text { 12 } \\
12 \\
2 \\
\text { (mutant) }\end{array}$ & $\begin{array}{l}9.5 \\
9 \cdot 5 \\
9.5 \\
9.5 \\
\ldots\end{array}$ \\
\hline
\end{tabular}

We can now consider the collective evidence provided by parental genotypes and progeny phenotypes and their ratios. Three identical mutants have been identified among garden parents (table 4), three in the progeny of one garden cross (table 6), and two probably identical mutants in a derivative of a cross between a species and garden form (table 7). The mutant gametes were $\mathrm{FIbH}, \mathrm{FIbH}$ and $\mathrm{FibH}$ respectively. In the second of the above categories, gene mutation of $i$ to $I$ appears to have occurred. In the other two categories the possibilities of crossing-over or mutation are various. In any case, the evidence suggests that $F, I, B$ and $H$ are specific units of a complex gene, each with independent phenotypic effects.

(iii) Lethality. The limited number of gametes determining flower pattern in garden forms of Streptocarpus requires further consideration. All the material employed in these studies originated from six plants 
(the gametic pool) chosen for their distinctive flower colours from Messrs Peed's strain of Streptocarpus :

I $/ 33$, white $\frac{f i b H}{f i b H} ; \quad 2 / 33$, blue $\frac{F I b h}{F I b h} ; \quad 3 / 33$, rose $\frac{F I b h}{F i B H}$; I5/34, salmon $\frac{F I b H}{F i B h} ;$ I6/34, magenta $\frac{F I b h}{F i B H} ;$ 18/36, petunia $\frac{F I b h}{F I b h}$.

Six other plants of Peed's strain were obtained later from a different source, but these proved the same, genotypically, as one or other of the first lot, so they were not used in the main breeding programme.

As will be seen by reference to table 3 , the gametic pool contains all the types identified (excluding the mutants) and no others. Because the pool is a small one, the existence of other types of gametes in garden Streptocarpus cannot be precluded, although perhaps it is unlikely. But the assumption that there are, apart from the mutants observed in these experiments, only three types of viable gamete in garden Streptocarpus assumes considerable significance when the constitution of the three species which were the parents (Lawrence and Sturgess, I95I) of the garden forms is considered, viz. rexii, FiBH; dunnii, FIbh; parviflorus, fibH, i.e. precisely the same as those of the only three types of gametes found in the garden forms. The corollary of this assumption is that all, or nearly all, other gametes are lethal in the garden forms. (Other combinations of the supergene components occur in other species.) Each parental combination of the supergene is balanced, recombination resulting in gametic lethality.

Further light is thrown on gametic behaviour by noting the inheritance of $H$ and $h$. When $\frac{F I b h}{F i B H}$ plants were selfed, the ratios of $H$ to $h$ were good 3 : I's (table 2), but when $\frac{F I b h}{f b H}$ plants were selfed, the ratios were abnormal, the total numbers from 25 different families being $F h 263 ; F H$ 912; fH 637, i.e. approximately $3: 10: 7$ when expectation was $I: 2: I$. This result cannot be explained merely by supposing that some of the $\frac{F I b h}{F I b h}$ zygotes were lethal as this would not account for the excess numbers of the $f H$ class. On the other hand, a fair approximation to the actual $F_{2}$ ratio is got if we deduce coefficients of "viability" such that $f i b H=\mathrm{I} \cdot \mathrm{O}$ and $F I b h=:$ $0 \cdot 64$.

Applied to the gametes only, the coefficients could be a measure of certation, e.g. $f b H$ pollen-tubes grow more quickly down the styles than FIbh and, on the average, compete successfully in fertilisation in the ratio $c a .1 \cdot 0: 0 \cdot 64$. On the other hand, the product coefficients could be a measure of average zygotic viability. Large differences in vegetative vigour occur among the garden Streptocarpus ranging from luxuriant growth to sub-lethality, e.g. inability to survive uıder 
excellent conditions of cultivation for more than a few months. Cilearly it is a small step from this sub-lethality, to lethality at some point between fertilisation and seed germination, the evidence for which we shall now examine.

Firstly, examples of zygotic lethality are seen in families $14 / 35$, $92 / 37$ and $82 / 38$ (table 4 ) in which no $\frac{F I b H}{F I b H}$ mutant genotypes occurred when the expected numbers were $18 \cdot 5,12 \cdot 5$ and $7 \cdot 25$ respectively.

TABLE 8

\begin{tabular}{|c|c|c|c|c|c|}
\hline \multicolumn{6}{|c|}{ Differential viability of $\frac{\text { FIbh }}{\text { FIbh }}$ zygotes } \\
\hline \multicolumn{2}{|c|}{ Parents } & \multicolumn{4}{|c|}{ Progeny } \\
\hline \multirow{2}{*}{ Female } & \multirow{2}{*}{ Male } & \multirow{2}{*}{ Expected types } & \multirow{2}{*}{$\begin{array}{l}\text { Number } \\
\text { observed }\end{array}$} & \multicolumn{2}{|c|}{ Number expected } \\
\hline & & & & $\begin{array}{l}\text { Full } \\
\text { viability }\end{array}$ & $\begin{array}{l}\text { Zygotic } \\
\text { lethality }\end{array}$ \\
\hline${ }^{6} / 53 \frac{F i B H}{F I b h}$ & $14^{1 / 34} \frac{f i b H}{F I b h}$ & $\begin{array}{l}1 / 54 \frac{F i B H}{f i b H} \\
\frac{F i B H}{F I b h} \\
\frac{F I b h}{f i b h} \\
\\
\overline{F I b h} \\
\overline{F I b h}\end{array}$ & $\begin{array}{l}18 \\
11 \\
9 \\
0\end{array}$ & $\begin{array}{l}9.5 \\
9.5 \\
9.5 \\
9.5\end{array}$ & $\begin{array}{l}12 \cdot 7 \\
12 \cdot 7 \\
12 \cdot 7 \\
0\end{array}$ \\
\hline${ }_{1}^{6} / 53 \frac{F i B H}{F l b h}$ & selfed & 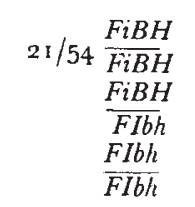 & $\begin{array}{l}\text { I I } \\
20 \\
\text { I }\end{array}$ & $\begin{array}{r}8 \cdot 0 \\
16 \cdot 0 \\
8 \cdot 0\end{array}$ & $\begin{array}{c}10.7 \\
21 \cdot 3 \\
0\end{array}$ \\
\hline
\end{tabular}

The $F I b H$ gamete must be assumed to be viable since, in the same families, it functioned to give reasonably good ratios in combination with $f b H$ and $F I b h$ gametes, hence it was the homozygote $\frac{F I b H}{F I b H}$ that was lethal. Secondly, in family $285 / 39$ (table 4 ) there were no $\frac{F i B H}{F I b H}$ individuals when the expected number was I2.5. Thus the FIbH gamete appears to be lethal in some zygotic combinations and viable in others. Thirdly, no $\frac{F I b h}{F I b h}$ progeny were found in family I I $/ 54$ (table 8 ) when the expected number was 9.5 ; and in family $21 / 54$ there was only one member of this class when expectation was $8 \cdot 0$. Since 65 garden forms have been found to have the constitution $\frac{F I b h}{F I b h}$, 
differential zygotic lethality must be postulated to account for this and the other results mentioned above.

The results of the experiments on the above four pairs of factors concerned with flower pattern in the garden forms may be summarised as follows :-

(I) $F, I, B$ and $H$ and their recessives are components of a supergene.

(2) With very rare exceptions the only viable gametes are those in which the components are identical with those of the three species known to be the parents of the garden forms.

(3) Certain combinations of the parental types of gamete result in zygotic sub-lethality.

(4) Three types of mutant gametes comprising new combinations of the components of the supergene have proved to be viable. Under glasshouse conditions, one mutant is lethal in the homozygous phase and with two of the three parental gametes, but viable with the third. The second mutant is viable in the homozygous phase and with the two parental gametes tested. The third mutant was not tested.

\section{(b) Inheritance of $\mathrm{L}$}

Narrow lines of anthocyanin are commonly found on the three posterior petals of both cyanic and acyanic flowers of Streptocarpus. These lines start just outside the throat of the flower and run down the corolla tube half-way or more. They may be continuous or somewhat broken. A common pattern is $2-3-2$ with respect to the number of lines found on the three lower petals. In acyanic $(V f)$ flowers the lines are very conspicuous; in cyanic flowers they are more decply coloured than the petals and vary from being well-marked to barcly discernible. In some individuals the middle posterior petal is without lines and those on the adjacent petals are broken and somewhat diffused, forming "side-bands". Both the $2-3-2$ and side-band patterns are controlled by the $L$ gene, the differences in pattern presumably being due to modifying genes.

The summarised results for the inheritance of $L$ in acyanic garden forms are given in table 9 . In $\mathrm{B}_{1}$ and $\mathrm{F}_{2}$ agreement with expectation is satisfactory in acyanic forms and the data are homogencous. In cyanic forms recessives are deficient in number, the $F_{2}$ ratio being $6.35 L: 1 \cdot 0 l$ and $B_{1}$ I.54 $L: 1 \cdot 0 l$. These ratios are of the order that would be expected if a common gametic factor is operating, e.g. if $l$ gametes participate in fertilisation less frequently than $L$ gametes, in the ratio $c a .1 \cdot 0 l: 0.6 \mathrm{I} l$. The similarity of this ratio to the coefficient of 0.64 for FIbh participation in fertilisation (p. 345 ) is of note. Examination of all relevant data has failed to reveal any specific connection between the deficiency of $l l$ and FIbh genotypes. The origin of $l$ is obscure, e.g. the ancestral species are all $L$. Probably, it is a mutant that has arisen under cultivation and which shows differential viability in $F$ genotypes. 


\section{(c) Inheritance of $Y$}

A central yellow stripe, $\frac{1}{16}$ to $\frac{1}{4}$ inch wide, runs from the limb down the posterior side of the corolla tube in many garden Streptocarpus.

TABLE 9

Inheritance of $\mathrm{Ll}$ in acyanic garden forms

\begin{tabular}{|c|c|c|c|c|c|}
\hline \multirow{2}{*}{$\begin{array}{l}\text { No. of } \\
\text { families }\end{array}$} & \multirow{2}{*}{$X: x$} & \multicolumn{2}{|c|}{$\chi^{2}$} & \multirow{2}{*}{ D.F. } & \multirow{2}{*}{$p$} \\
\hline & & $\begin{array}{l}\text { Deviation } \\
\text { from } X: x\end{array}$ & Heterogeneity & & \\
\hline 8 & $\begin{array}{c}B I \\
\text { I I } 5: 137\end{array}$ & $\begin{array}{l}I: I \\
I \cdot 92 \mathrm{I}\end{array}$ & $\begin{array}{c}\cdots \\
13 \cdot 215\end{array}$ & $\begin{array}{l}1 \\
7\end{array}$ & $\begin{array}{l}0.5-0.1 \\
0.1=0.05\end{array}$ \\
\hline 12 & $\begin{array}{c}F_{2} \\
\mathrm{I} 98: 6 \mathrm{I}\end{array}$ & $\begin{array}{l}3: I \\
0 \cdot 072\end{array}$ & $\begin{array}{c}\cdots \\
\text { I3.2I } 5\end{array}$ & $\begin{array}{l}\text { I } \\
\text { I I }\end{array}$ & $\begin{array}{l}0.8-0 \cdot 7 \\
0.3-1 \cdot \cdot 2\end{array}$ \\
\hline
\end{tabular}

TABLE 10

Inheritance of yellow stripe, $\mathrm{Y}_{1} \mathrm{Y}_{2}$ in garden forms

\begin{tabular}{|c|c|c|c|c|c|c|}
\hline \multirow{2}{*}{ Genes } & \multirow{2}{*}{$\begin{array}{l}\text { No. of } \\
\text { families }\end{array}$} & \multirow{2}{*}{$X: x$} & \multicolumn{2}{|c|}{$\chi^{2}$} & \multirow{2}{*}{ D.F. } & \multirow{2}{*}{$p^{2}$} \\
\hline & & & $\begin{array}{l}\text { Deviation } \\
\text { from } X: x\end{array}$ & $\begin{array}{l}\text { Hetero- } \\
\text { geneity }\end{array}$ & & \\
\hline $\begin{array}{l}r_{I y I} \\
r_{2 y 2}\end{array}$ & 5 & $\begin{array}{c}B_{I} \\
230: 25^{3} \\
315: 306\end{array}$ & $\begin{array}{l}I: I \\
\mathrm{I} \cdot 607 \\
0 \cdot 130\end{array}$ & $\begin{array}{c}\cdots \\
2 \cdot 366 \\
\cdots \\
0 \cdot 4^{8} 7\end{array}$ & $\begin{array}{l}I \\
4 \\
1 \\
3\end{array}$ & $\begin{array}{r}0.3-0 \cdot 2 \\
0 \cdot 7-0 \cdot 5 \\
0 \cdot 8-0 \cdot 7 \\
0.3\end{array}$ \\
\hline $\begin{array}{l}r_{I y I} \\
r_{2 y 2}\end{array}$ & 24 & $\begin{array}{c}F_{2} \\
47: 46 \\
928: 360\end{array}$ & $\begin{array}{c}3: I \\
29 \cdot 680 \\
6 \cdot 146\end{array}$ & $\begin{array}{c}\cdots \\
\mathrm{I} \cdot 320 \\
\cdots \\
29 \cdot 82 \mathrm{I}\end{array}$ & $\begin{array}{r}1 \\
2 \\
1 \\
23\end{array}$ & $\begin{array}{c}\text { v. small } \\
0 \cdot 7-0.5 \\
0 \cdot 02-0 \cdot 01 \\
0.2\end{array}$ \\
\hline$\Upsilon_{I y I} \Upsilon_{2 y 2}$ & 4 & I $86:$ I 76 & $\begin{array}{l}9: 7 \\
3.487\end{array}$ & $\begin{array}{c}\cdots \\
0.971\end{array}$ & $\begin{array}{l}\text { I } \\
3\end{array}$ & $\begin{array}{l}0 \cdot 1-0.05 \\
0.9-1) \cdot 8\end{array}$ \\
\hline
\end{tabular}

This character is controlled by two dominant complementary genes, $\Upsilon_{I}$ and $\Upsilon_{2}$, such that $\Upsilon_{I}\left(\Upsilon_{I}\right)_{2} y_{2}$ and ${ }_{1} y_{I} \Upsilon_{2}\left(\Upsilon_{2}\right)$ phenotypes lack the yellow stripe, whereas $\Upsilon_{I}\left(\mathscr{Y}_{I}\right) \Upsilon_{2}\left(\Upsilon_{2}\right)$ has it. The breeding results (table Io) are in good agreement with expectation in backcrosses but, as with $F$, in $\mathrm{F}_{2}$ the class totals are only moderately good and tntal and familv heterogeneity values are disturbed. 


\section{(d) Linkage}

No systematic attempt was made to determine linkages of flower pattern genes and the results given in table 5 are merely those that came to hand. Linkage of $F, I, B$ and $H$ has been discussed and is complete, or almost entirely so. The other pattern genes, $L, \Upsilon_{I}$ and

TABLE II

Inheritance of $\mathrm{Ll}$ in species $\times$ garden forms

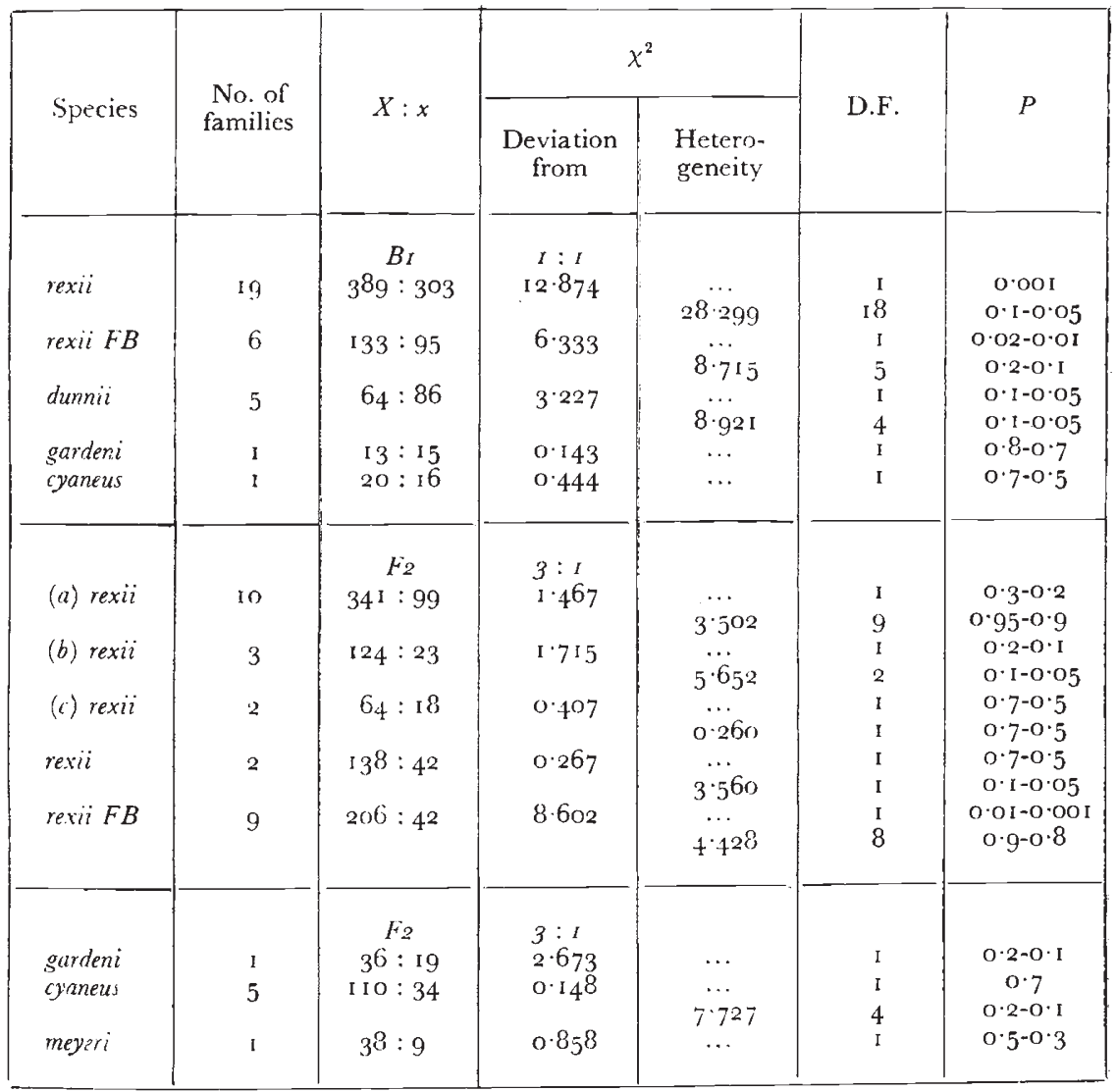

$(a),(b)$ and $(c)=$ crosses with different test plants.

$\Upsilon_{2}$ also exhibit linkage, crossing-over apparently being of the order 20-30 per cent. $L$ is linked with $D$ but not with $\Upsilon_{2}\left(B_{1}=\right.$ $20 L Y: 32 L y: 23 l Y: 23 l y)$. $L$, therefore, should show linkage with $Y_{I}$ but no data exist to test this. Only tentative assumptions can be made about the linear order of the genes on the chromosome which, with approximate cross-over values, seems to be as follows :-

$$
\text { FIBH } 30 \text { ? } \quad C Y_{2} \quad 20 \quad D \quad 25 \quad Y_{I} \quad(L \text { ? })
$$

The inheritance of $L$ is independent of that of $O, F, B$ and $H$ and the inheritance of $\gamma_{I}$ and $\gamma_{2}$ independent of that of $O$ and $R$ (Lawrence and Sturgess, 1957). 


\section{PATTERN IN THE SPECIES}

\section{General anthocyanin}

Evidence for the Mendelian inheritance of $V, F$ and $I$ in families derived from crosses between rexii and rexii $F B$ on the one hand and

TABLE 12

Inheritance of yellow stripe in interspecific crosses

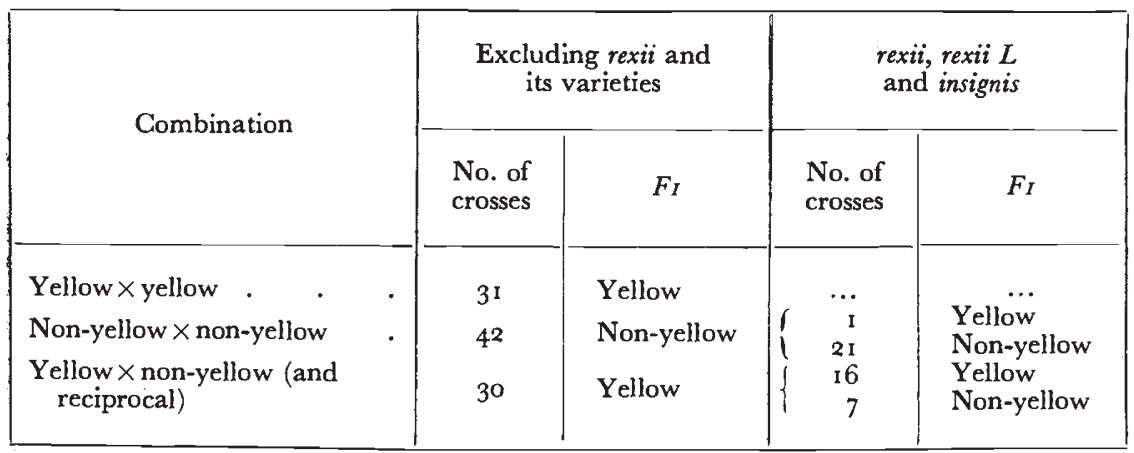

TABLE I 3

Constitution for $\mathrm{Yy}$ of some non-yellow species

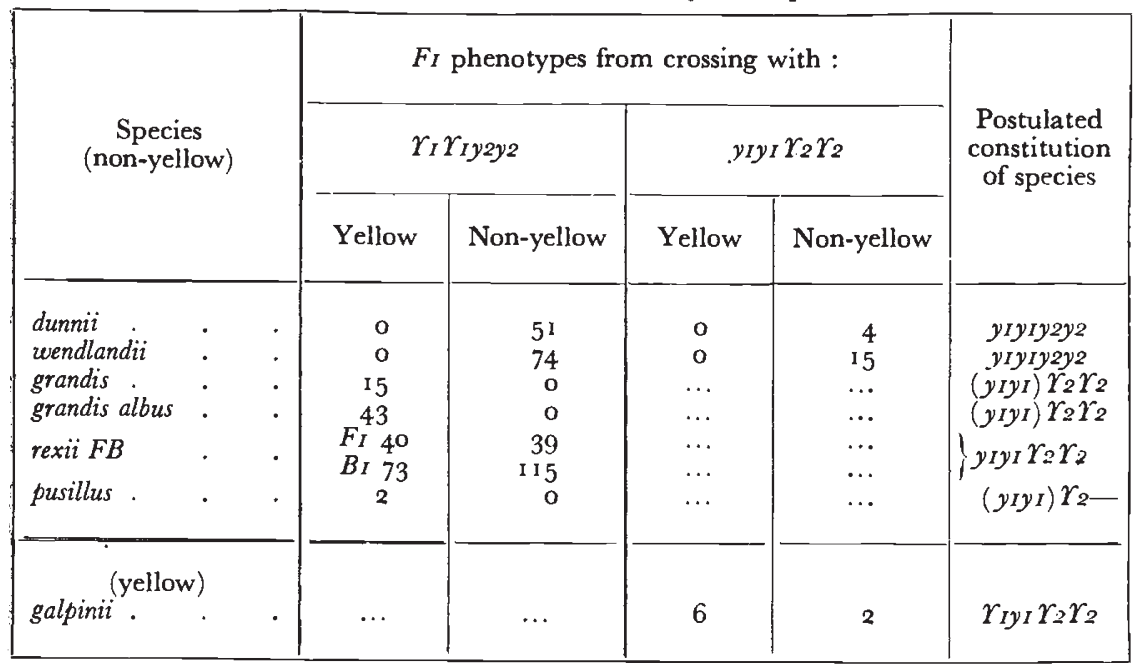

Brackets $=$ inferred constitution.

garden forms on the other, was presented in Lawrence and Sturgess, I957, page 305 and earlier in this paper (tables 7 and 8). In addition, three $\mathrm{F}_{1}$ individuals with cyanic flower stems, derived from rexii (cyanic stems, $V V$ ) $\times$ dunnii (acyanic stems, vv) backcrossed to dunnii, gave a total of 178 plants with cyanic and 47 with acyanic stems $\left(\chi^{2} ; 3:\right.$ I ratio, $\mathrm{P}=0 \cdot 05-0 \cdot \mathrm{I})$. Clearly, there is either a large deficiency of recessives in the backcross, or at least one other pair of alleles is involved. In the latter event, a $3:$ I ratio would be obtained in $\mathrm{B}_{1}$ if rexii were $V V W W$ and dunnii voww, $V$ and $W$ being supplementary genes producing anthocyanin in the stems. 
Evidence for the constitution of the three species parents of the garden forms is as follows. With rexii, $\frac{F i B H}{F i B H}$ backcross ratios were obtained of $8_{3} B: 6_{3} b$ and $47 H: 3^{8} h$ and an $\mathrm{F}_{2}$ of $58 H:$ i $7 h$. Two $\overline{F I b h}$ garden forms $\times$ dunnii gave $4^{2}$ and $30 \mathrm{~F}_{1}$ plants respectively, all bh. dunnii lacks the corolla tube blotch $(B)$ and coloured capitate hairs $(H)$ on the pistil, and may therefore be assigned the constitution $\frac{F I b h}{F I b h}$. Crossed to a $b h$ garden form, parviftorus gave $30 \mathrm{~F}_{1}$ plants, all $b H$; therefore this species is $f b H$.

\section{(a) Lines}

The expression of the line character, $L$, in species crosses is straightforward : $64 L \times L$ families and $33 L \times l$ were all lined and 21 $l \times l$ all unlined. A summary for the inheritance of $L$ in 5 distinctive species is given in table II. Often there is a deficiency of recessives; nevertheless it is highly probable that inheritance of the line pattern is governed by a single gene.

Although the data are not sufficiently extensive to permit a firm. conclusion, it is probable that ( $\mathrm{I}$ ) the anthocyanin patterns as found in the species are controlled by genes $B, H$ and $L$ homologous to those studied comprehensively in the garden forms, and (2) the inheritance of these genes is monohybrid as in the garden forms.

\section{(b) Yellow stripe}

The position regarding the complementary genes $Y_{I}, Y_{2}$ for yellow throat is more complex :-

(I) Excluding crosses with rexii, yellow was inherited as if it were a simple dominant over non-yellow (table I2), but with varying degrees of expression.

(2) In crosses involving rexii, rexii $L$ and insignis, yellow crossed non-yellow gave 16 yellow $F_{1}$ 's and 7 non-yellow (rexii itself, 9 yellow and 4 non-yellow).

(3) The $F_{1}$ 's from crossing rexii, rexii $L$ and insignis with garden forms of various constitutions for $Y$ were variable, but in general yellow was largely or totally suppressed. Indeed, sometimes the yellow pattern was not recovered in $B_{1}$ and $\mathrm{F}_{2}$ families numbering $50-70$ individuals. This is what might be expected if rexii etc., carried a suppressor of yellow along with some recessive $y$ genes.

(4) Species lacking the yellow pattern may carry $r_{I}$ or, alternatively, $r_{2}$. This has been shown by crossing such species to $y_{1 y} r_{2} r_{2}$ and $r_{1} \Upsilon_{I y 2 y 2}$ garden forms, respectively (table I3). Although a complete investigation of the constitution of rexii was not possible, the evidence from $B_{2}$ 
suggests that this species does in fact carry $r$ genes, and is probably $--\Upsilon_{2} \Upsilon_{2}$. This assumption accords with $F_{I}$ and $B_{I}$ evidence from the acyanic rexii $F B$.

The general conclusion, therefore, is that yellow behaves as a simple $F_{I}$ dominant in all species crosses excepting rexii and the closely related rexii $L$ and insignis, these species being characterised by an hereditary factor which tends strongly to suppress yellow.

\section{(c) Dunnione}

This is a colouring matter, $\beta$-naphthaquinone, which occurs as an orange-red deposit on the leaves and inflorescences, but not the flowers, of dunnii (Price and Robinson, 1940). The same pigment, apparently, is also found on pole-evansii. In rexii $\times$ dunnii $\mathrm{F}_{1}$ 's dunnione is completely recessive. Backcrosses to dunnii gave a total of 63 unpigmented : 83 pigmented plants $\left(\chi^{2} \mathrm{I}: \mathrm{I}, \mathrm{P}=0 \cdot \mathrm{I}\right.$; Het. $\left.\chi^{2} \mathrm{P}=0.07\right)$ and inheritance is, therefore, monohybrid.

\section{(d) Filament colour}

The anther filaments in all of the species examined, save three, are pure white or white faintly tinged with purple anthocyanin (polyanthus, johannis). The three exceptions are michelmorei and eylesii which have deep purple filaments and dunnii which has green, i.e. pigmented with chlorophyll. In four different $F_{1}$ 's, michelmore $i \times$ garden forms (white filaments), the filaments were coloured, though not so deeply as in michelmorei. The green filaments of dunnii are unique in Streptocarpus. In crosses with garden forms (and with rexii), white is completely dominant to green in $F_{1}$ and the total numbers from I 4 families backcrossed to dunnii were 197 white filament : 249 green.

In summary, the results of these studies point to the following conclusions : (I) the inheritance of all the flower patterns is probably monohybrid obscured in some instances by the results of interspecific hybridity, (2) the genes carried by the species are homologous with those found in the garden forms, and (3) genes dominant in the garden forms are usually dominant in the species-a similar situation to that found in the inheritance of the flower colour characters and genes. The species comprising Streptocarpus $\left(2 n=3^{2}\right)$ are, therefore, functional diploids.

\section{PATTERN IN THE GENUS}

The frequency and distribution of seven flower pattern genes and characters are given in table 14 . The species are classified on a morphological basis discussed in a paper to follow.

Two major findings emerge from this generic survey. The first relates to the genes $F, I, B$ and $H$ and their recessives which are seen to vary in their combinations among the species. In the context of this paper, the three parent species of the garden forms were a random 
sample from the genus and all carried $F, I, B$ and $H$, or their recessives, combined as a supergene. Therefore there is no reason to suppose that these genes do not occur combined as a supergene in other species,

TABLE 14

Frequency and distribution of flower pattern genes and characters in Streptocarpus

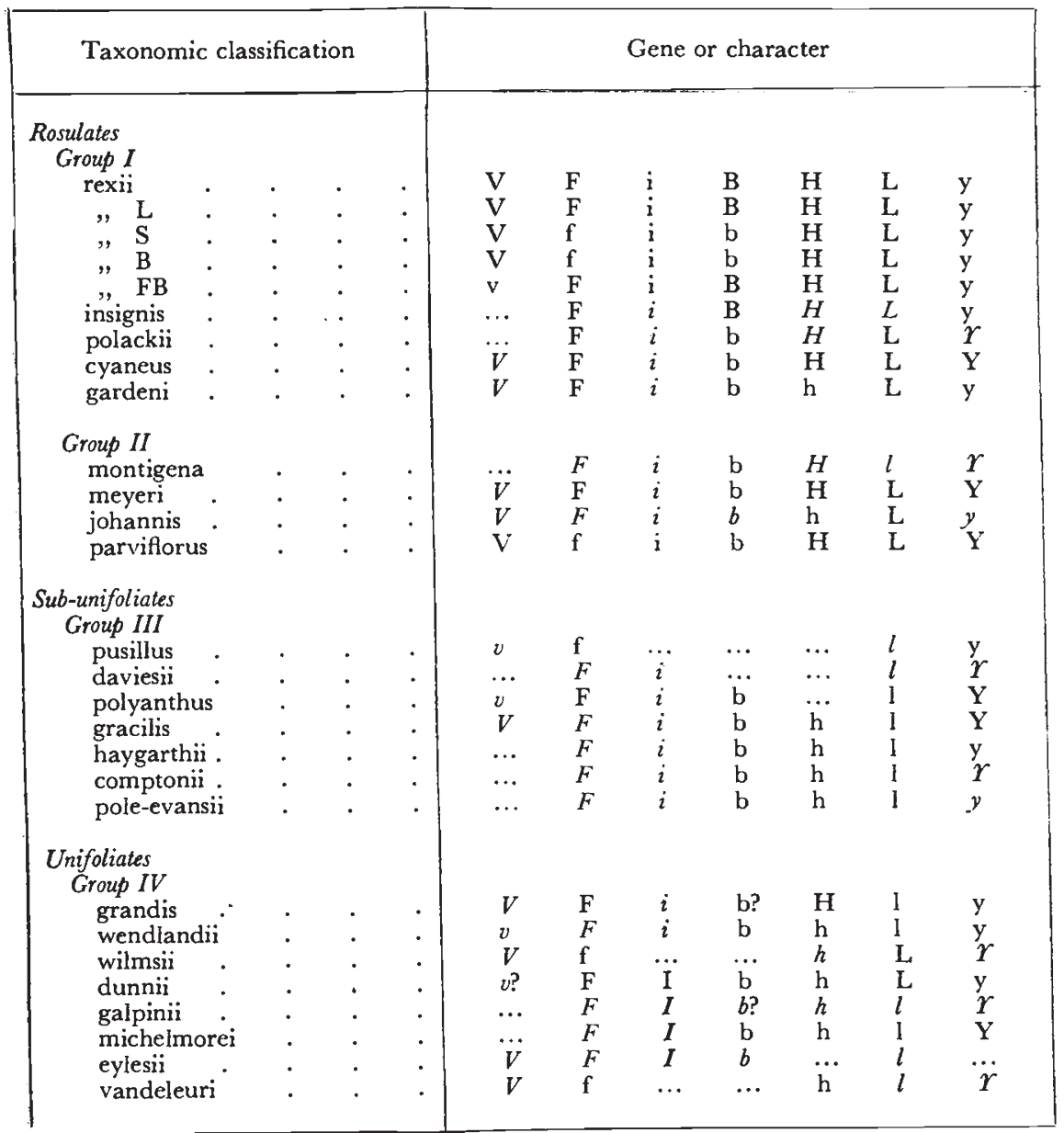

Roman type $=$ identified by breeding. Italic type $=$ identified by inspection.

indeed perhaps in all. If they do, then from table 14 it is evident that, in addition to the three combinations characterising rexii, parviflorus and dunnii, viz. FiBH, fibH and FIbh, two others are common, viz. FibH and Fibh.

The second fact emerging from the survey is that the distribution of the flower pattern genes in general is not random. $I$ is found only in the unifoliates; $B$ only in group I rosulates, indeed only in the rexii types in this group; $H$, with one exception, only in the 
rosulates. Further, all group I species carry $L$ and all group III $l$ and it seems that this group may all be $i, b, h, l$. Lastly, the cyanic rexii types are all $i, B, H, L, y$. Thus species which have been classified into groups on gross morphological criteria are found to be characterised also by their genotypes for flower pattern.

\section{DISCUSSION}

\section{Origin of garden forms}

The origin of the garden forms from artificial crosses made seventy years ago by W. Watson at the Royal Botanic Gardens, Kew, between rexii (pale-blue flowers), parviflorus (white) and dunnii (red) is authentic and the crosses between the parent species and the subsequent development of the garden forms are well recorded and illustrated (Hortus Veitchii, I906). In developing the garden forms, nurserymen selected the rosulate habit of rexii (and parviflorus) and the redder and/or deeper flower colours made available by the use of dunnii. To the eye, the habit, leaves and inflorescences of the garden forms closely resemble rexii; therefore the eventual contribution of dunnii to flower colour and pattern has been the genes $o R$ and $d$ determining the various anthocyanin colours (Lawrence and Sturgess, I957) and the FIbh supergene concerned with flower pattern.

These genes from dunnii have been incorporated into the rexii genome with unmistakable consequences. First, the three parental combinations of the supergene components, $F i B H, F I b h$ and $f i b H$, have remained virtually intact after seventy years of strong selection mainly because mutation of, or crossing-over between, the component units results in gametic or zygotic lethality. Secondly, homozygous garden forms identical with the ancestral species with regard to the supergene, e.g. $\frac{F I b h}{F I b h}$ are no more viable or vigorous, often less so, than other classes, e.g. $\frac{F i B H}{f i b H}$. Thus, the FIbh supergene is in harmony with the dunnii genome but not with that of the garden forms, i.e. the rexii genome. The incorporation of the supergenes from dunnii and parviflorus has resulted in a cryptic genotypic complexity which has not been resolved by seventy years of breeding. Indeed the differential zygotic viability and vigour are the overt expression of a hidden genetic unbalance, as also are the deviating ratios. In this last respect there is a close resemblance between the inheritance of flower colour and pattern in the garden Streptocarpus and the garden Verbena, also of interspecific origin, in which close linkages occur with exceptional frequency (Beale, 1940).

Although the experiments have demonstrated the individual dominance relations of $F, I, B$ and $H$ and their recessive alleles, they did not go far enough to establish whether each of the four genes is independent in mutation, though independence of $I$ seems clear 
(p. 34I). Neither was it possible to establish the linear order of the genes on the chromosomes, but the fact that two wild, white-flowered varieties of rexii, rexii $S$ and rexii $B$, are apparently both $f b$ whereas the cyanic species, rexii, rexii $L$, also insignis, are all $F B$, suggests that these two pairs of alleles are juxtaposed ( $c f$. also parviflorus). On this point it may be significant that the other wild variety of rexii, rexii $F B$, which has white flowers, because it is recessive for the independently inherited gene $V$, is $F B$ in constitution.

\section{Flower pattern as an adaptive mechanism}

The demonstration that the components of the supergene exist in three different combinations in the three morphologically different species which are the parents of the garden forms, each from distinctly different habitats, suggests that the specific combinations have arisen in response to specific elements of the habitats. Thus, insect pollinators may differ from habitat to habitat. Or the flower pattern of a given species may be the one that is most conspicuous against the particular environmental background, e.g. woodland or veldt. In this connection it should be noted that other combinations of the supergene occur in the genus, especially in species from habitats unrelated to those of the ancestors of the garden forms. An alternative view would be that the aggregation of the pattern genes into a supergene was primarily not a direct response to the external environment but an expression of the interdependence of the genes in the control of other essential processes. Whatever the causal mechanism there is little doubt that different species are characterised by a particular combination of co-adapted supergene components.

Taking each of the four genes in turn in the dominant and recessive phases, the total number of possible combinations is sixteen. Two questions are obvious. Do all sixteen occur in the genus; and what features, if any, are common to species carrying the same combination? Other patterns may, of course, be controlled by additional components of the supergene, e.g. anthocyanin colour in the stigma. Taking the evidence as a whole it seems not unlikely that the supergene constitutes an isolation mechanism.

Flower colour and pattern as the products of evolution

The genetic systems controlling flower colour and flower pattern in Streptocarpus are in striking contrast. Flower colour is governed by a number of genes whose inheritance is characteristically independent whereas the genes controlling flower pattern are all linked. In flower colour, gene interaction, denoting synthesis of the pigments from a common precursor or precursors, results in a pigment syndrome in which the different dominant and epistatic genes apparently reinforce one another to maintain high levels of chemical activity and of phenotypic stability. The unifying element, so to speak, is gene interaction. In flower pattern, the unifying element is linkage. 
A further difference between colour and pattern relates to wild types. With colour, one type, blue (malvidin 3:5-dimonoside) predominates almost exclusively. With pattern, there are a number of wild types comprising, to some extent, groups of species. Thus, colour is widely adapted, pattern much more specifically so.

In this connection, it is of interest that rexii and dunnii differ with respect to $l, B$ and $H$, but are alike for $F$, i.e. they differ for highly specific anthocyanin patterns (including intensity) but not for general anthocyanin production.

\section{CONCLUSION}

Six flower pattern characters studied in the garden forms of Streptocarpus are all linked in inheritance, four of them as a supergene in which linkage is complete. The supergene comprises dominant and recessive "alleles" in three combinations only and these are identical with those found in the species known to be the parents from which the garden forms were originally derived by artificial hybridisation. Other species carry other combinations of the supergene and are also characterised, individually and in taxonomic groups, by their flower pattern genes in general.

\section{SUMMARY}

I. A survey is made of the occurrence of six flower patterns in garden forms and species hybrids in Streptocarpus, and of the geographical distribution of these patterns among the species in the wild. Inheritance of the patterns is Mendelian.

2. The gene $F$ is necessary for the general production of anthocyanin in the flowers and $I$ intensifies the colour. $B$ produces a blotch of anthocyanin in the corolla tube and $H$ produces anthocyanin in the stalks of the capitate hairs borne on the pistil. $L$ controls the production of anthocyanin in lines running down the throat and $r_{I}$, $\gamma_{2}$ are complementary genes governing a yellow throat stripe.

3. $F, I, B$ and $H$ and their recessives are completely linked in specific combinations and comprise a supergene. Eight anomalous forms are shown to have arisen by rare mutation or crossing-over.

4. Only three types of the supergene are found in the garden Streptocarpus and these are identical with those of the three species, the hybridisation of which gave rise to the garden forms seventy years ago, viz. rexii FiBH, parviflorus fibH, and dunnii FIbh. Zygotic lethality and sub-lethality result from certain combinations of the components of the supergene.

5. The supergene is linked with $Y_{2}$, and apparently $Y_{I}$ is linked with $L$, the cross-over values being 20-30 per cent. Linkage, therefore, may be said to be characteristic of the flower pattern genes in Streptocarpus, whereas independent inheritance is characteristic of the flower colour genes. 
6. The distribution of the flower pattern genes in the wild is not random, individual species and taxonomic groups being characterised by different combinations of genes and supergene, including those given above.

\section{REFERENCES}

BE.ALE, G. H., PRICE, T. R., AND SCOTT-MONCRIEFF, R. I940. The genetics of Verbena.

II. Chemistry of the flower colour variations. F. Genet., 4I, 65-74.

Hortus Veitchii. 19o6. London, pp. 503-506.

LAWRENCE, W. J. C., AND STURGESS, v. c. I957. Studies on Streptocarpus. III.

Genetics and chemistry of flower colour in the garden forms, species and hybrids. Heredity, II, 303-336.

price, J. R., AND robinson, R. I940. Dunnione, Part II. 7. Chem. Soc., pp. 1493I499. 